\title{
Isotopic evidence for the moisture origin and composition of surface runoff in the headwaters of the Heihe River basin
}

\author{
ZHAO LiangJu ${ }^{1,2,3 *}$, YIN Li ${ }^{1}$, XIAO HongLang ${ }^{1}$, CHENG GuoDong $^{2}$, ZHOU MaoXian ${ }^{1}$, \\ YANG YongGang ${ }^{1}$, LI CaiZhi $^{1} \&$ ZHOU Jian ${ }^{2}$ \\ ${ }^{1}$ Key Laboratory of Ecohydrology of Inland River Basin, Cold and Arid Regions Environmental and Engineering Research Institute, Chinese \\ Academy of Sciences, Lanzhou 730000, China; \\ ${ }^{2}$ State Key Laboratory of Frozen Soil Engineering, Cold and Arid Regions Environmental and Engineering Research Institute, Chinese Academy \\ of Sciences, Lanzhou 730000, China; \\ ${ }^{3}$ Heihe Upstream Watershed Ecology-Hydrology Experimental Research Station, Cold and Arid Regions Environmental and Engineering \\ Research Institute, Chinese Academy of Sciences, Lanzhou 730000, China
}

Received June 7, 2010; accepted October 27, 2010

\begin{abstract}
We investigated the moisture origin and contribution of different water sources to surface runoff entering the headwaters of the Heihe River basin on the basis of NECP/NCAR (National Centers for Environmental Prediction/National Center for Atmospheric Research) re-analysis data and variations in the stable hydrogen and oxygen isotope ratios $\left(\delta \mathrm{D}\right.$ and $\left.\delta^{18} \mathrm{O}\right)$ of precipitation, spring, river, and melt water. The similar seasonality in precipitation $\delta^{18} \mathrm{O}$ at different sites reveals the same moisture origin for water entering the headwaters of the Heihe River basin. The similarity in the seasonality of $\delta^{18} \mathrm{O}$ and $d$-excess for precipitation at Yeniugou and Urumchi, which showed more positive $\delta^{18} \mathrm{O}$ and lower $d$-excess values in summer and more negative $\delta^{18} \mathrm{O}$ and higher $d$-excess values in winter, indicates a dominant effect of westerly air masses in summer and the integrated influence of westerly and polar air masses in winter. Higher $d$-excess values throughout the year for Yeniugou suggest that in arid inland areas of northwestern China, water is intensively recycled. Temporal changes in $\delta^{18} \mathrm{O}, \delta \mathrm{D}$, and $d$-excess reveal distinct contributions of different bodies of water to surface runoff. For example, there were similar trends for $\delta \mathrm{D}, \delta^{18} \mathrm{O}$, and $d$-excess of precipitation and river water from June to September, similar $\delta^{18} \mathrm{O}$ trends for river and spring water from December to February, and similar trends for precipitation and runoff volumes. However, there were significant differences in $\delta^{18} \mathrm{O}$ between melt water and river water in September. Our results show that the recharge of surface runoff by precipitation occurred mainly from June to mid-September, whereas the supply of surface runoff in winter was from base flow (as spring water), mostly with a lower runoff amount.
\end{abstract}

\section{$\delta \mathrm{D}, \delta^{18} \mathrm{O}$, moisture sources, surface runoff, headwaters of the Heihe River basin}

Citation: Zhao L J, Yin L, Xiao H L, et al. Isotopic evidence for the moisture origin and composition of surface runoff in the headwaters of the Heihe River basin. Chinese Sci Bull, 2011, 56: 406-416, doi: 10.1007/s11434-010-4278-x

Precipitation is a primary input for the water cycle. Spatial and temporal variations in stable hydrogen and oxygen isotope ratios ( $\delta \mathrm{D}$ and $\delta^{18} \mathrm{O}$ ) in precipitation can provide important clues to the origins of water and the climatic conditions under which it formed [1-4]. It is well known that heavy isotopes $\left(\delta^{18} \mathrm{O}\right.$ and $\left.{ }^{2} \mathrm{H}\right)$ in water vapor are depleted more easily than lighter isotopes $\left({ }^{16} \mathrm{O}\right.$ and $\left.{ }^{1} \mathrm{H}\right)$ as a result of

*Corresponding author (email: zhlj@1zb.ac.cn) rainfall from a mass of moist air during its long-distance transport. As a result, $\delta \mathrm{D}$ and $\delta^{18} \mathrm{O}$ in precipitation become more negative with increasing distance along the transportation path [5]. At the same time, parallel fractionation is destroyed owing to kinetic fractionation processes during water evaporation, resulting in differences in the relationship between $\delta \mathrm{D}$ and $\delta^{18} \mathrm{O}$. Dansgaard [2] defined this difference as the "deuterium excess" $\left(d\right.$-excess $\left.=\delta \mathrm{D}-8.0 \delta^{18} \mathrm{O}\right)$, which averages about 10.0 on a global scale. The $d$-excess 
in precipitation as a result of kinetic fractionation during water evaporation is mainly influenced by the relative humidity and temperature of the area where the moisture originated [6-8]. Merlivat and Jouzel [6] and Johnsen et al. [9] indicated that the $d$-excess in moisture from evaporation increases with increasing temperature and decreasing relative humidity above the sea surface. Therefore, the $d$-excess in precipitation has many applications in hydrology because the degree of kinetic fractionation provides clues to the moisture origin [10]. Many factors affect the $\delta^{18} \mathrm{O}, \delta \mathrm{D}$, and $d$-excess values of precipitation, including geographical factors (latitude, altitude, and distance from the coast) [2], meteorological factors (temperature, relative humidity, and precipitation) $[11,12]$, and the water's origin and transport mechanisms $[13,14]$. By analyzing $\delta^{18} \mathrm{O}$ and $d$-excess in regional precipitation, we can therefore detect the water's origin $[15,16]$, monitor patterns of the atmospheric circulation of water [17-19], and determine the extent of recharge of surface water [20,21] and groundwater [22] by precipitation, as well as the correlations among these processes [23].

Many researchers have studied water cycles in the Heihe River basin on the basis of patterns of isotopes [24-29]. In the headwaters area of the Heihe River basin, researchers have found significant temperature effects [29], but also marked altitude effects [26], on precipitation $\delta^{18}$ O. Seasonal variation in $\delta^{18} \mathrm{O}$ of precipitation and river water has shown that mountain runoff into the main stream of the Heihe River was mostly contributed by precipitation in the Qilian Mountains [27]. However, there has been no research on the contributions of precipitation, melt water, and spring water to surface runoff that enters the headwaters of the Heihe River basin. Similarly, there have been no reports on the origin of water in the Heihe River basin and its adjacent zones that integrate the spatial and temporal variation in precipitation $\delta^{18} \mathrm{O}$ with the NECP/NCAR (National Centers for Environmental Prediction/National Center for Atmospheric Research) re-analysis data. In the present study, we combined NECP/NCAR re-analysis data with seasonal variations in $\delta^{18} \mathrm{O}, \delta \mathrm{D}$, and $d$-excess for precipitation, river water, and spring water, and with spatial variations in $\delta \mathrm{D}$ and $\delta^{18} \mathrm{O}$ for river water, melt water, and spring water. Our goal was to determine the origins of water in the headwaters of the Heihe River basin and the contribution of different water sources to surface runoff during the year. Our results will provide basic data on the water cycle in the Heihe River basin.

\section{Study area}

The inland river basin in northwestern China is characterized by a scarcity of water resources, and severe deterioration of the water environment has already adversely affected the possibility of sustainable regional development. The Heihe River, China's second-largest inland river, originates on the northern slopes of the Qilian Mountains, and the main stream has a length about $821 \mathrm{~km}$. The Heihe River basin is the second largest inland river basin in northwestern China, having a drainage area of $1.3 \times 10^{5} \mathrm{~km}^{2}$. The basin includes the montane zone of the Qilian Mountains, the Hexi Corridor plains in the middle, and the lower montane zone and Alashan Plateau in the north, and borders the Badain Jaran Desert in the east. The altitude of the upper reaches of the Heihe River ranges from 1700 to $5564 \mathrm{~m}$, and the climate is cold and moist. The annual mean temperature varies from $-5^{\circ} \mathrm{C}$ to $4^{\circ} \mathrm{C}$. The annual total precipitation averages more than $200 \mathrm{~mm}$, and increases to between 600 and $700 \mathrm{~mm}$ at higher altitudes. The annual melt water totals about $4 \times 10^{8} \mathrm{~m}^{3}$. In the middle and lower reaches, annual total precipitation is less than $200 \mathrm{~mm}$ and $50 \mathrm{~mm}$, respectively. About $90 \%$ of the water resources in the middle and lower reaches are therefore recharged by mountain water, and the river is mainly replenished by surface runoff from the mountains.

Our study area was located in the upper reaches of the Heihe River basin. Two long-term observation sites are located at the Yeniugou weather station and at Mafengou in the western part of the river's main stream, and another station is located at Dayekou, in the middle of the Qilian Mountain. Both Mafengou and Dayekou are observation stations of the Cold and Arid Regions Environmental and Engineering Research Institute, Chinese Academy Sciences. In the headwaters of the Heihe River basin, the primary mountain runoff is generated in the drainage of the western part of the main stream because precipitation tends to decrease from the southeast to the northwest [30]. The mean runoff into the western part of the main stream accounts for $78.7 \%$ of the total in the upper reaches. In the 1990s, the surface runoff of the Zhamashenke and Yingluoxia Rivers accounted for $18.8 \%$ and $42.9 \%$ of the total runoff in the headwaters, respectively. Observation data from 40 stations within the basin, operated by the Hydrological Bureau of Gansu Province, revealed that sites recording precipitation of more than $300 \mathrm{~mm}$ were all located near the western part of the main stream. Based on this data, the drainage area in the western part of the main stream is the primary catchment in the Heihe River basin. We therefore selected this region as the main area for our intensive sample collection. The Yeniugou station is located near the middle of the western main stream $\left(99^{\circ} 38^{\prime} \mathrm{E}, 38^{\circ} 42^{\prime} \mathrm{N}\right.$, at an elevation of $3320 \mathrm{~m}$ ). The annual precipitation from 1959 to 2000 averaged $401.4 \mathrm{~mm}$, with $80 \%$ of the rainfall occurring from June to September. The annual mean temperature averages about $-3.1^{\circ} \mathrm{C}$, with the lowest monthly mean temperature being recorded in January $\left(-17.2^{\circ} \mathrm{C}\right)$ and the highest monthly mean temperature in July $\left(9.2^{\circ} \mathrm{C}\right)$. The temperature is above $0^{\circ} \mathrm{C}$ from May to September. Dayekou is located in the middle of the Qilian Mountains $\left(100^{\circ} 17^{\prime} \mathrm{E}, 38^{\circ} 34^{\prime} \mathrm{N}\right.$, at an elevation of $2720 \mathrm{~m}$ ). The meteorological data recorded by the Dayekou station gave a highest July temperature of 
$12.2^{\circ} \mathrm{C}$ and lowest January temperature of $-12.9^{\circ} \mathrm{C}$, with a mean annual temperature of $0.7^{\circ} \mathrm{C}$. Annual precipitation averages $369.2 \mathrm{~mm}$.

\section{Water sampling and analysis}

Figure 1 shows the locations of our sampling sites.

Precipitation samples: Precipitation samples were collected at Yeniugou and Dayekou. At the Yeniugou weather station, precipitation was sampled (by event) from June 2008 to February 2009 and from June to September 2009. At the Dayekou hydrological station, precipitation was sampled (by 2 or 4 h) from July to August 2009, and at the Dayekou field observation stations, precipitation was sampled (by event) from September to November 2008.

River water samples: River water samples were collected weekly from the Zhamashenke River (main stream) from May to December in 2008 and from April to November in 2009. River water samples were also collected from the Batougou branch of the Zhamashenke River from July to October 2008 and from July to November 2009. In addition, river water samples were taken from the headwaters of the Heihe River basin in May 2008 and June 2009.

Spring and melt water: Samples of spring and melt water were taken from the headwaters of the Heihe River basin in May 2008 and in June, August, and September 2009. In addition, spring water samples were collected weekly at Mafengou from August 2009 to February 2010. All samples were obtained at about 4:00 pm. Two replicates were obtained for each sample. Before sampling, we washed the glass sample vial (with a capacity of $8 \mathrm{~mL}$ ) three times using the sampled water, and then filled it with the water sample. Each vial was sealed immediately with Parafilm to prevent evaporation.

Analysis of stable oxygen and hydrogen isotopes: The $\delta^{18} \mathrm{O}$ and $\delta \mathrm{D}$ values for the water samples were measured at the Key Laboratory of Ecohydrology of the Inland River Basin, Cold and Arid Regions Environmental and Engineering Research Institute, Chinese Academy of Sciences. Samples taken from January 2008 to February 2009 were measured using a GV Instruments Isoprime and Euro EA3000 system. Some samples were also measured at Nagoya University to confirm the accuracy of the Isoprime measurements, using a Delta Plus mass spectrometer (Thermo Finnigan) with a $\mathrm{H}_{2} \mathrm{O}-\mathrm{H}_{2}$ equilibrium method for $\delta^{18} \mathrm{O}$ and with a hydrophobic platinum catalyst for $\delta \mathrm{D}$. Samples taken in 2009 and 2010 were measured using an L1102-I isotopic water analyzer (Picarro, Sunnyvale, CA) to compare with the previous results. To avoid the memory effect associated with continuous-flow methods, measurements of each sample were repeated five times, and the first two values were discarded. The accuracy was better than $\pm 1.0 \%$ for $\delta \mathrm{D}$ and $\pm 0.2 \%$ for $\delta^{18} \mathrm{O}$ in the case of the Isoprime system and $\pm 0.5 \%$ for $\delta \mathrm{D}$ and $\pm 0.1 \%$ ofor $\delta^{18} \mathrm{O}$ in the case of the L1102-I system. $\delta^{18} \mathrm{O}$ and $\delta \mathrm{D}$ were calibrated using two international standard materials (VSMOW and GISP or SLAP) and one working standard. The $\delta^{18} \mathrm{O}$ and $\delta \mathrm{D}$ values are expressed in \%o units relative to the V-SMOW value [31].

\section{Results and discussion}

\subsection{Isotopic evidence for the origins of moisture entering the headwaters of the Heihe River basin}

(i) Variation in precipitation $\delta \mathrm{D}$ and $\delta^{18} \mathrm{O} . \quad \delta \mathrm{D}$ and $\delta^{18} \mathrm{O}$

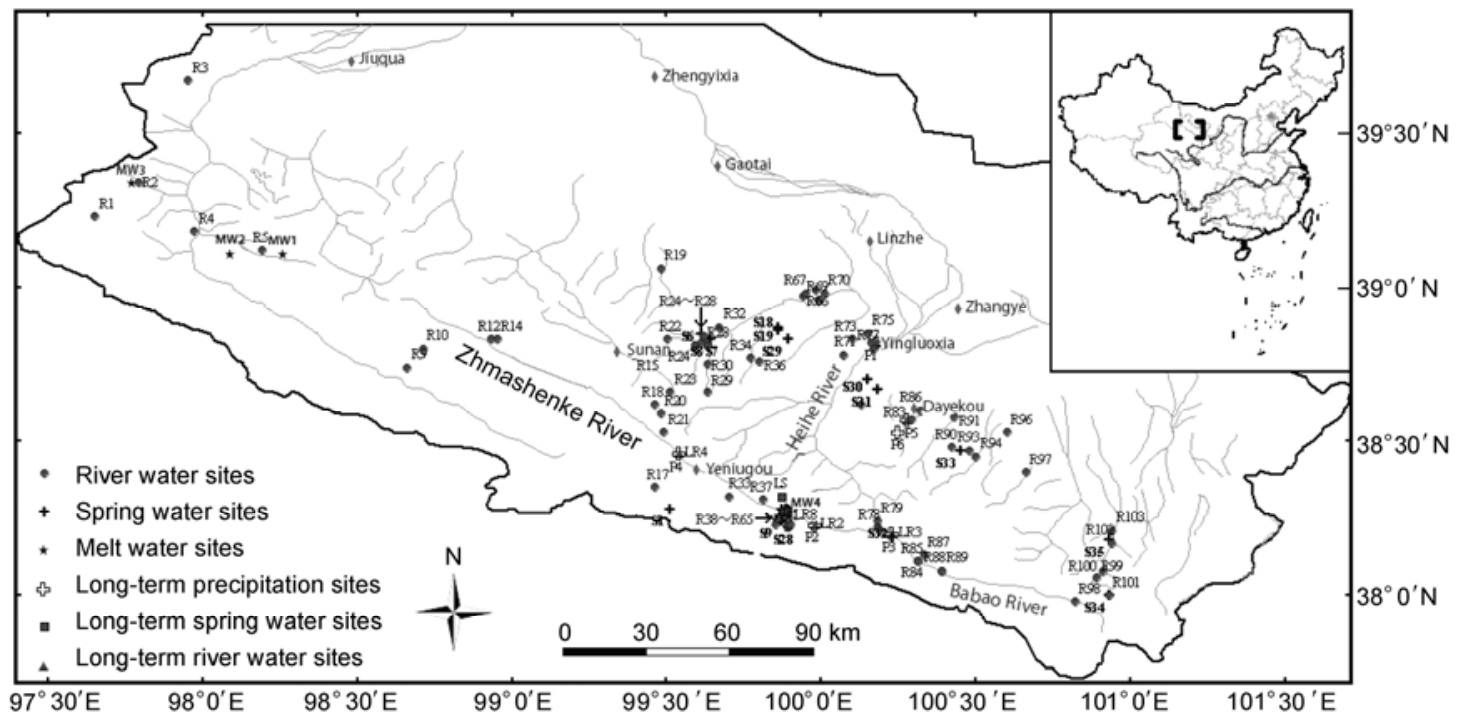

Figure 1 Map showing the study area and locations of sampling sites in the headwaters of the Heihe River basin. Rx indicates river water sampling sites; $\mathrm{P} x$ and LR $x$ represent long-term precipitation and river water sampling sites, respectively; S $x$ and LS $x$ represent spring water and long-term spring water sampling sites, respectively; MWx represents melt water sampling sites in the upper reaches of the Heihe River basin. The data of sites MW1 to MW3 and sites R1 to R5 were cited from Zhang et al. [28]. 
for the precipitation collected at both Yeniugou and Dayekou exhibited similar patterns of variation, with there being more positive values from June to the middle 10 days of September and more negative values from the last 10 days of September to February (Figure 2(a),(b); Table S1). For example, $\delta^{18} \mathrm{O}$ and $\delta \mathrm{D}$ for precipitation at Yeniugou from June to the middle 10 days of September averaged $-4.6 \%$ o and $-24.6 \%$, respectively, in 2008 versus $-4.7 \%$ and $-22.7 \%$ in 2009 . After the last 10 days of September, $\delta^{18} \mathrm{O}$ and $\delta \mathrm{D}$ for precipitation averaged $-18.1 \%$ and $-120.9 \%$, respectively, in 2008 versus $-12.8 \%$ and $-82.0 \%$ in 2009 . At Dayekou, $\delta^{18} \mathrm{O}$ and $\delta \mathrm{D}$ for precipitation averaged $-1.7 \%$ and $-15.6 \%$, respectively, before the middle 10 days of September, versus $-10.0 \%$ and $-67.9 \%$ from the middle 10 days of September to November. The similar patterns of variation in precipitation $\delta^{18} \mathrm{O}$ and $\delta \mathrm{D}$ indicate the same moisture sources in the headwaters of the Heihe River basin. In addition, precipitation $\delta \mathrm{D}$ and $\delta^{18} \mathrm{O}$ became more negative with increasing duration of the precipitation event (boldfaced data in Table S1). For example, $\delta^{18} \mathrm{O}$ and $\delta \mathrm{D}$ for precipitation became gradually more negative from 26 July to 1 August 2008, reaching minima of $-22.1 \%$ or for $\delta^{18} \mathrm{O}$ and $-125.3 \%$ for $\delta \mathrm{D}$ (Figure 2(a), (b); Table S1). This is because the moisture during a given rain event came from the same air mass. At the beginning of the precipitation event, water vapor enriched in $\delta^{18} \mathrm{O}$ and ${ }^{2} \mathrm{H}$ would generate the rain, but as precipitation continued, the rain was progressively depleted in $\delta^{18} \mathrm{O}$ and ${ }^{2} \mathrm{H}$. For instance, more positive $\delta^{18} \mathrm{O}$ and $\delta \mathrm{D}$ were recorded even though there was much precipitation $(8.7 \mathrm{~mm})$ during the 26 July event. Owing to the low atmospheric relative humidity and strong evaporation effect during the condensation and precipitation of the rain, precipitation $\delta^{18} \mathrm{O}$ and $\delta \mathrm{D}$ were more positive because the water vapor was enriched in $\delta^{18} \mathrm{O}$ and ${ }^{2} \mathrm{H}$ at the beginning of the precipitation event. However, on 31 July, with little precipitation $(2.1 \mathrm{~mm})$, precipitation $\delta^{18} \mathrm{O}$ and $\delta \mathrm{D}$ were $-17.4 \%$ and $-125.3 \%$, respectively (Figure 2(a), (b); Table S1). We can explain this on the basis of leaching and Rayleigh distillation effects during the rainfall, which deplete the amounts of $\delta^{18} \mathrm{O}$ and ${ }^{2} \mathrm{H}$ in the water [32]. From 31 July to 1-2 August, variations in precipitation $\delta \mathrm{D}$ and $\delta^{18} \mathrm{O}$ measured at intervals of 2 hours also revealed a strong leaching effect (samples labeled 09-7-p and 09-8-p in Table S1).

The $d$-excess values for the precipitation are related to kinetic fractionation during evaporation, and are influenced by air temperature and relative humidity during evaporation [6-8]. The precipitation $d$-excess after the last 10 days of September increased more rapidly than that before the first 10 days at both Yeniugou and Dayekou (Figure 2(c)). For example, at Yeniugou, the precipitation $d$-excess from June to the middle 10 days of September averaged $12.1 \%$ in 2008 and $14.7 \%$ in 2009 . However, after the last 10 days of September, the precipitation $d$-excess averaged $23.9 \%$ in

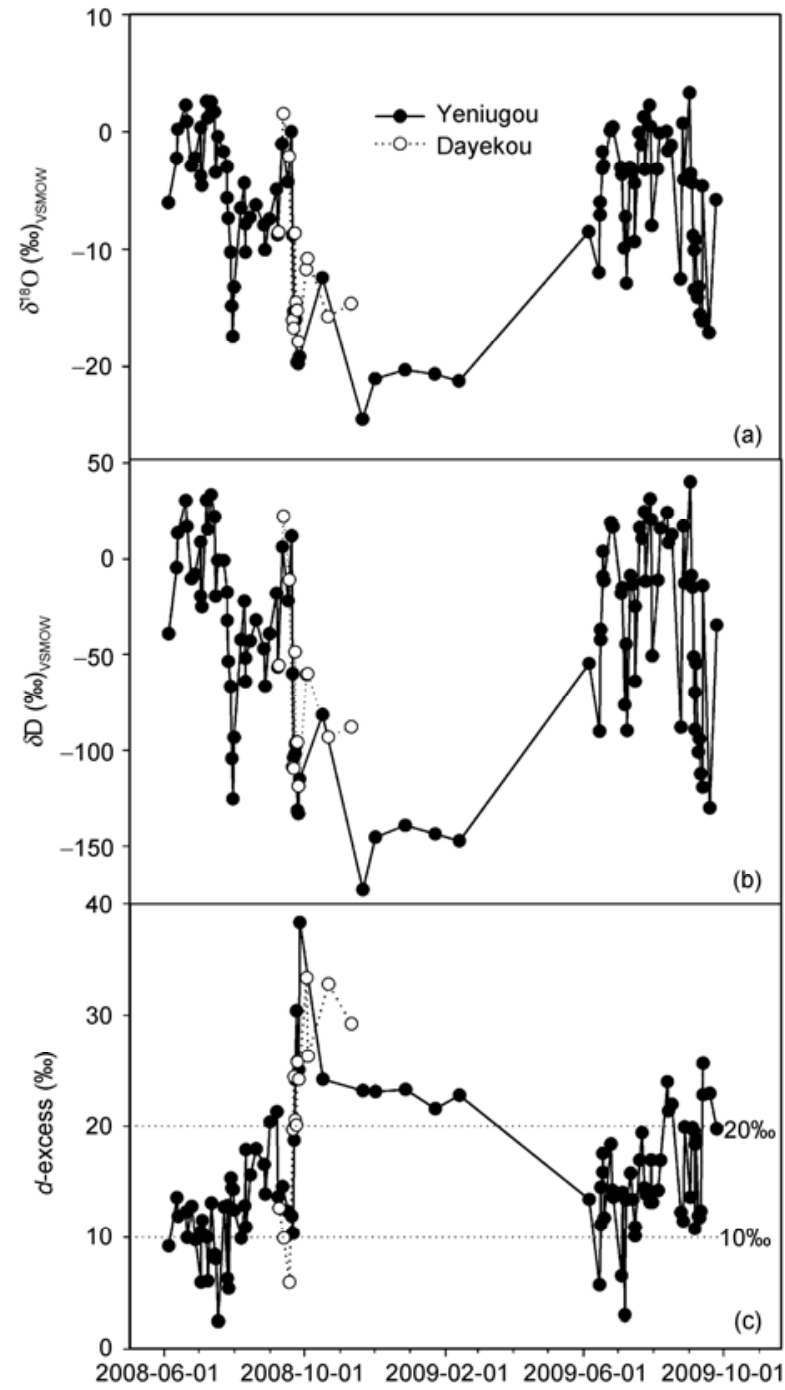

Figure 2 Variations in (a) $\delta^{18} \mathrm{O}$, (b) $\delta \mathrm{D}$, and (c) $d$-excess for precipitation at the Yeniugou and Dayekou stations in 2008 and 2009 in the headwaters of the Heihe River basin.

2008 and $20.7 \%$ in 2009. At Dayekou, the precipitation $d$-excess averaged $9.5 \%$ from August to the first 10 days of September versus $25.6 \%$ from the middle 10 days of September to November (Figure 2(c)), suggesting that variations in the precipitation $d$-excess were related to the moisture origin and local relative humidity in the headwaters of the Heihe River basin.

The slopes of the local meteoric water lines (LMWLs) at Yeniugou (7.647) and Dayekou (7.163) were gentler than that of the global meteoric water line (GMWL: 8), and the intercept of the Yeniugou LMWL (12.396) was higher and that of the Dayekou LMWL (5.695) was lower than that of the GMWL (10.0) (Figure 3). These results suggest that moisture sources for the headwaters of the Heihe River basin mainly related to atmospheric circulation patterns, but that local climatic factors such as re-evaporation of raindrops during precipitation and seasonality of precipitation 


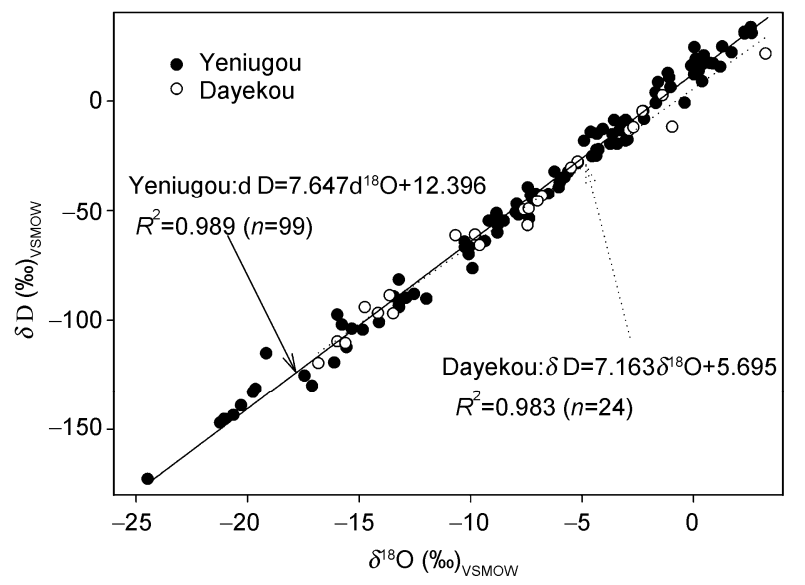

Figure 3 Scatterplots of $\delta \mathrm{D}$ versus $\delta^{18} \mathrm{O}$ for precipitation at Yeniugou and Dayekou in the headwaters of the Heihe River basin.

also affected the precipitation isotope ratios. The gentler slope of the LMWL at Dayekou than at Yeniugou indicates stronger evaporation at Dayekou. This can be explained by the warmer mean temperatures at Dayekou $\left(0.7^{\circ} \mathrm{C}\right)$ than at Yeniugou $\left(-3.1^{\circ} \mathrm{C}\right)$. Wang et al.[26] and Zhang and $\mathrm{Wu}$ [29] also reported that precipitation $\delta \mathrm{D}$ and $\delta^{18} \mathrm{O}$ responded positively to temperature in the headwaters of the Heihe River basin.

The seasonality of the precipitation $\delta^{18} \mathrm{O}$ and $d$-excess values reveal that as a result of weak evaporation due to high precipitation, high relative humidity, and low temperature (Figure 4(a),(b)), precipitation $\delta^{18} \mathrm{O}$ values for Yeniugou were more negative than those for Zhangye, except during May and June (Figure 4(b)). The $d$-excess value is generally closely related to evaporation processes. In addition to evaporation conditions at the moisture origin, the re-evaporation of falling raindrops can also affect the precipitation $d$-excess [8,33]. The much lower $d$-excess values for Zhangye than for Yeniugou (Figure 4(b)) suggest stronger re-evaporation of raindrops during precipitation.

(ii) Correlations between seasonal variations in precipitation $\delta \mathrm{D}, \delta^{18} \mathrm{O}$, and $d$-excess and moisture sources. Given the sparse sampling sites and short observation period in the present study, we supplemented our data with data from a previous study [27] and found good consistency of results, with there being similar seasonality patterns (i.e. higher $\delta^{18} \mathrm{O}$ in the summer and lower $\delta^{18} \mathrm{O}$ in the winter; Figure 5 ). Thus, the mean precipitation $\delta^{18} \mathrm{O}$ values reveal the origins of the moisture entering the headwaters of the Heihe River basin. By combining our data with the NCEP/NCAR reanalysis datasets and the ranges of China's monsoon zones [34], we were able to propose origins for the water entering the headwaters. Using the NCEP/NCAR reanalysis datasets, we calculated the wind and humidity fields at 500 hPa in July 2008 and November 2009 (Figure 6), which represent the summer and winter moisture origin conditions, respectively. In both seasons, the water sources near the

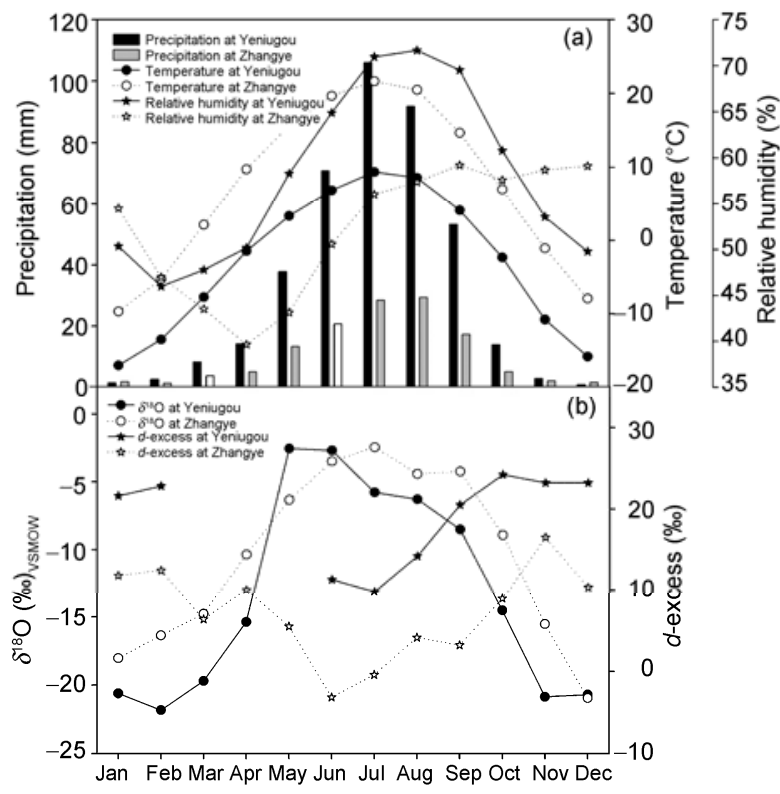

Figure 4 Comparison of (a) climatic factors and (b) precipitation $\delta^{18} \mathrm{O}$ and $d$-excess between Yeniugou and Zhangye. The climatic data for Yeniugou and Zhangye represent mean monthly values from 1959 to 2005 and from 1951 to 2007, respectively. Precipitation $\delta^{18} \mathrm{O}$ for Yeniugou are precipitation-weighted mean $\delta^{18} \mathrm{O}$ values, whereas the values for Zhangye are monthly $\delta^{18} \mathrm{O}$ values from the IAEA database (http://nds121.iaea.org/ wiser).

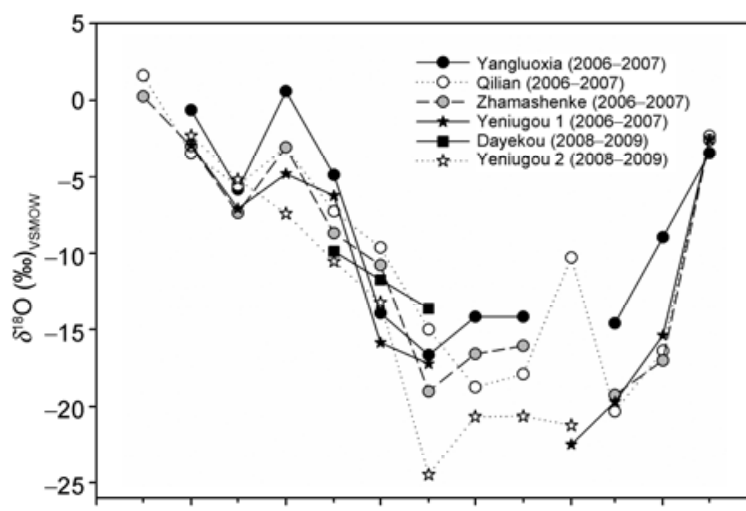

2006-04 2006-06 2006-08 2006-10 2006-12 2007-02 2007-04 2007-06

2008-04 2008-06 2008-08 2008-10 2008-12 2009-02 2009-04 2009-06

Figure 5 Seasonal variations in precipitation-weighted mean $\delta^{18} \mathrm{O}$ for the headwaters of the Heihe River basin. Data for Yeniugou 2 (May 2008 to February 2009 and May 2009 to September 2009) and Dayekou (September to November 2008) are from the present study. Data for Yingluoxia, Qilian, Zhamashenke, and Yeniugou 1 (May 2006 to May 2007) were cited from Wang et al. [27].

headwaters of the Heihe River basin and adjacent regions resulted predominantly from westerly air masses. However, the moisture in the study area was also derived partly from polar air masses during the winter. To more precisely determine the origin of the moisture entering the headwaters, we compared the seasonal variations in precipitation $\delta^{18} \mathrm{O}$ and $d$-excess for the headwaters with values for Urumqi 

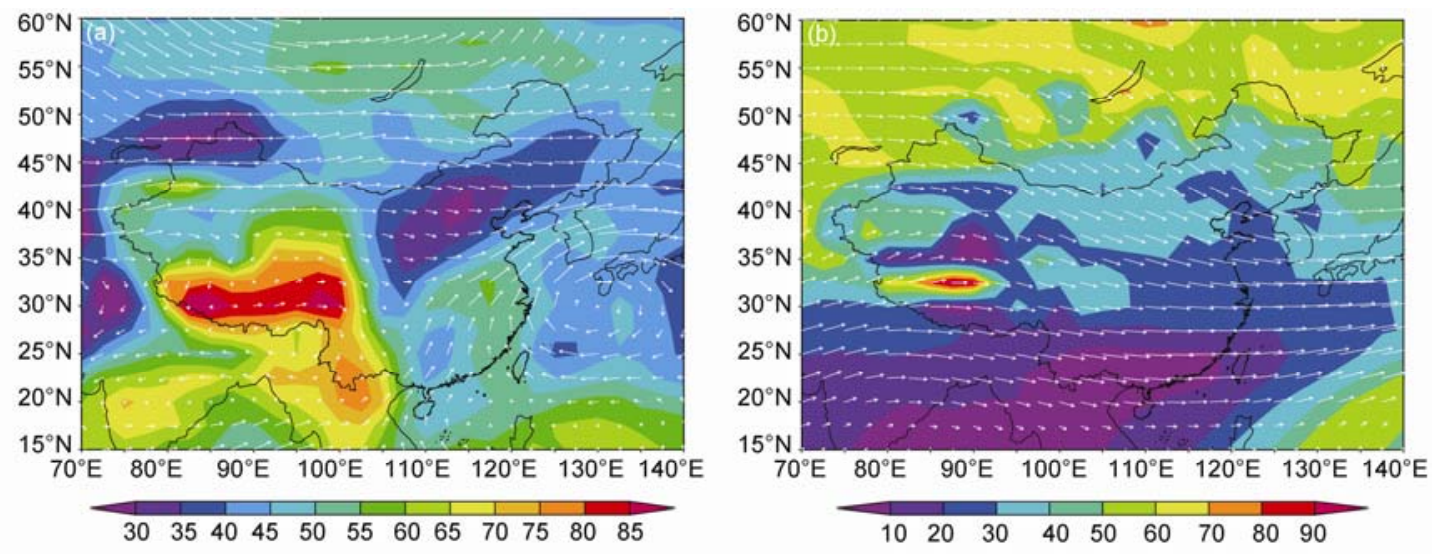

Figure 6 Spatial distributions of wind fields (arrows) and humidity fields (colors) at 500 hPa in July 2008 (a) and November 2009 (b) over China and adjacent regions. Arrows indicate wind direction and colors represent humidity $(\mathrm{g} / \mathrm{kg})$.

(affected by westerly air masses), Lhasa (affected by the southwest monsoon), and Hong Kong (affected by the southeast monsoon). We found similar seasonal variations in $\delta^{18} \mathrm{O}$ and $d$-excess for our study area and Urumqi (Figure $7(\mathrm{a})$, (b)), with there being more negative $\delta^{18} \mathrm{O}$ values in winter and more positive $\delta^{18} \mathrm{O}$ values in summer and the opposite pattern for $d$-excess. In summer, precipitation $\delta^{18} \mathrm{O}$ values for the headwaters of the Heihe River basin and urumgi were more positive than those for Lhasa and Hong Kong. Tian et al. [35] reported that extremely low $\delta^{18} \mathrm{O}$ values were related to intensive monsoon transport, and that high precipitation $\delta^{18} \mathrm{O}$ was related to local water recycling or transport from the north. Yu et al. [36] reported that in the Muztagata region of western China, high precipitation $\delta^{18} \mathrm{O}$ in the summer resulted from westerly air masses and local water circulation, both of which contributed to variations in the oxygen isotope ratios of precipitation. Thus, the more positive precipitation $\delta^{18} \mathrm{O}$ indicated that water from the summer monsoon had little effect on rain near the headwaters of the Heihe River basin in the summer. In winter, however, precipitation $\delta^{18} \mathrm{O}$ values for the headwaters of the Heihe River basin and Urumqi were more negative than those for Lhasa and Hong Kong. The marked differences among the monsoon zone, transition zone, and westerly zone in the Tibetan Plateau reported by Yao et al. [37] indicate that differences in these water sources strongly affected

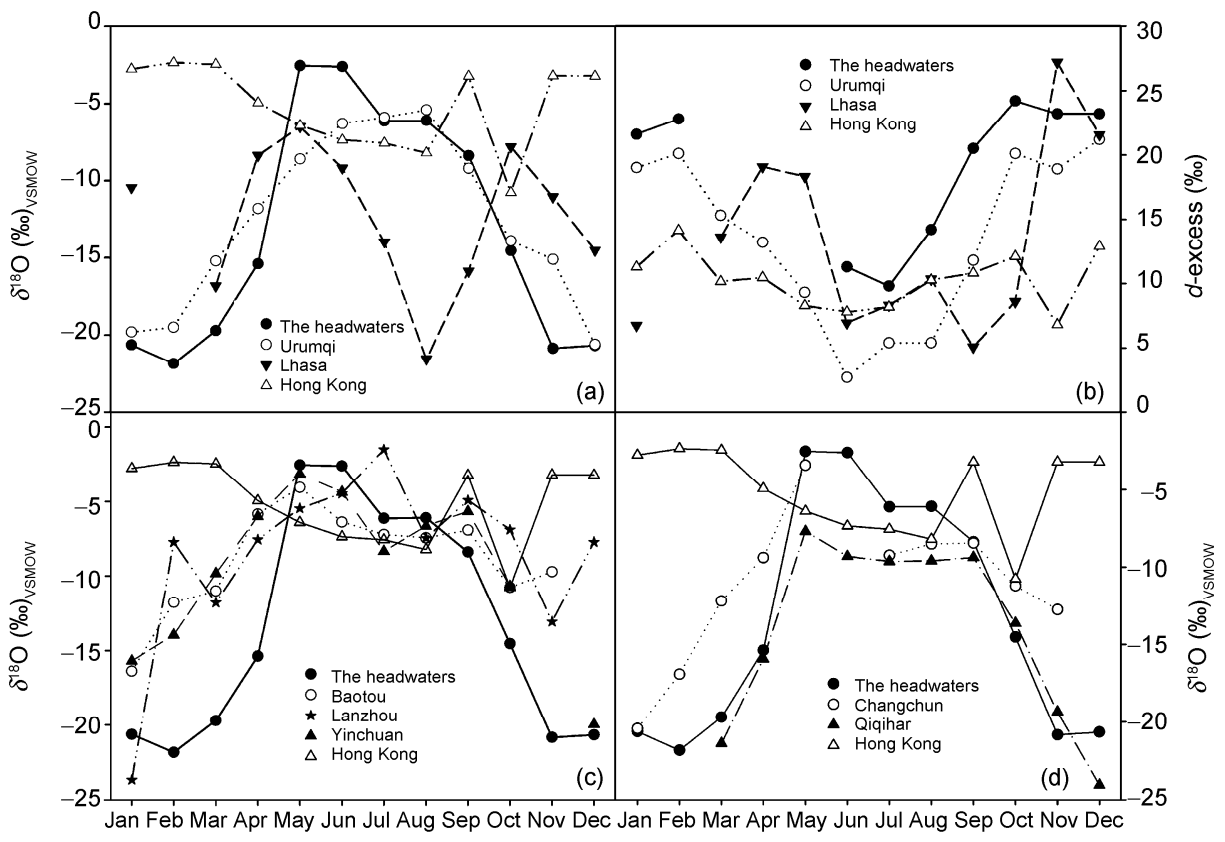

Figure 7 Comparison of seasonal trends in (a) precipitation $\delta^{18} \mathrm{O}$ and (b) precipitation $d$-excess among the headwaters of the Heihe River and Urumqi, Lhasa, and Hong Kong. Comparison of seasonal trends in precipitation $\delta^{18} \mathrm{O}$ between the headwaters of the Heihe River and locations in (c) northwestern and (d) northeastern China. The headwaters represent the upper reaches of the Heihe River basin, for which precipitation $\delta^{18} \mathrm{O}$ is the arithmetic means of the values from Wang et al. [27] and the values in the present study from 2008 to 2009. The precipitation $\delta^{18}$ O values for Lhasa, Urumqi, Hong Kong, Baotou, Lanzhou, Yinchuan, Changchun, and Qiqihar are from the IAEA database (http://nds121.iaea.org/wiser). 
precipitation $\delta^{18} \mathrm{O}$. The similar seasonal variations in precipitation $\delta^{18} \mathrm{O}$ for the headwaters of the Heihe River basin and for the westerly zone [37], and the dissimilarity with the variations for Lhasa and Hong Kong, reveal that the moisture entering the headwaters of the Heihe River basin was derived predominantly from the westerly and polar air masses. Precipitation $\delta^{18} \mathrm{O}$ for the headwaters of the Heihe River basin was generally more negative than that for Urumchi, suggesting $\delta^{18} \mathrm{O}$ and ${ }^{2} \mathrm{H}$ depletion in the water as a result of rainfall during long-distance transport [5]. In addition, the high precipitation $d$-excess values suggest that recycled water derived from local sources contributes significantly to winter precipitation [38]. This suggests intensive water recycling in the headwaters of the Heihe River basin [19].

We also compared our results with seasonal variations in precipitation $\delta^{18} \mathrm{O}$ for northwestern and northeastern China (Figure 7(c),(d)). Lanzhou, Baotou, and Yinchuan are in northwestern China and beyond the northern extent of the summer monsoon [39] and beyond the reach of the Pacific monsoon [38]. As a result, moisture is mainly provided by westerly air masses in the summer and by westerly and polar air masses from the north and northwest during the winter (Figure 6) [38], which is accordance with more positive precipitation $\delta^{18} \mathrm{O}$ in summer and more negative precipitation $\delta^{18} \mathrm{O}$ in winter. Precipitation $\delta^{18} \mathrm{O}$ for Yinchuan was more negative than that for Hong Kong in July (Figure 7(c)), suggesting a contribution of summer monsoon rains at Yinchuan in July [38]. From May to August, precipitation $\delta^{18} \mathrm{O}$ for Qiqihar and Changchun in northeastern China were more negative than values for the headwaters of the Heihe River basin and values for Hong Kong, suggesting that precipitation $\delta^{18} \mathrm{O}$ for these areas was controlled by the summer monsoon in summer. In other seasons, the variations in precipitation $\delta^{18} \mathrm{O}$ were similar to those for the headwaters of the Heihe River basin, suggesting the effects of westerly and polar air masses (Figure 7(d)). These results suggest that Qiqihar and Changchun are in the East Asian monsoon zone [39], and that water was derived from the summer monsoon during the summer and from the westerly and polar air masses during the winter (Figures 6 and 7(d)).

\subsection{Contribution of precipitation, melt water, and spring water to surface runoff}

(i) Correlations of $\delta^{18} \mathrm{O}$ and $\delta \mathrm{D}$ among different water pools. In the case of the headwaters of the Heihe River basin, the plots of $\delta^{18} \mathrm{O}$ versus $\delta \mathrm{D}$ for river, melt, and spring water were close to the LMWLs at Yeniugou and Dayekou (Figure 8), demonstrating that the surface water recharged from local precipitation. However, the ranges of $\delta \mathrm{D}, \delta^{18} \mathrm{O}$, and $d$-excess values for precipitation were larger than those for river water at Yeniugou. For example, in 2008 and 2009, precipitation $\delta^{18} \mathrm{O}, \delta \mathrm{D}$, and $d$-excess ranged from $-24.5 \%$ o to $3.3 \%$, from $-172.6 \%$ o to $40.2 \%$, and from $2.4 \%$ to $38.3 \%$, respectively. However, $\delta^{18} \mathrm{O}$ for river water ranged from $-8.8 \%$ to $-6.9 \%$ in 2008 and from $-8.2 \%$ o to $-6.8 \%$ in 2009 (Figure $9(\mathrm{a})$ ). $\delta \mathrm{D}$ for river water ranged from $-59.9 \%$ to $-40.4 \%$ in 2008 and from $-55.1 \%$ o to $-44.1 \%$ in 2009 (Figure 9(b)). The $d$-excess ranged from $10.5 \%$ to $19.2 \%$ or for the Zhamashenke River and from $4.9 \%$ to $13.5 \%$ for the Batougou River (Figure 9(c)). Our finding that the magnitudes of the variations in $\delta \mathrm{D}, \delta^{18} \mathrm{O}$,

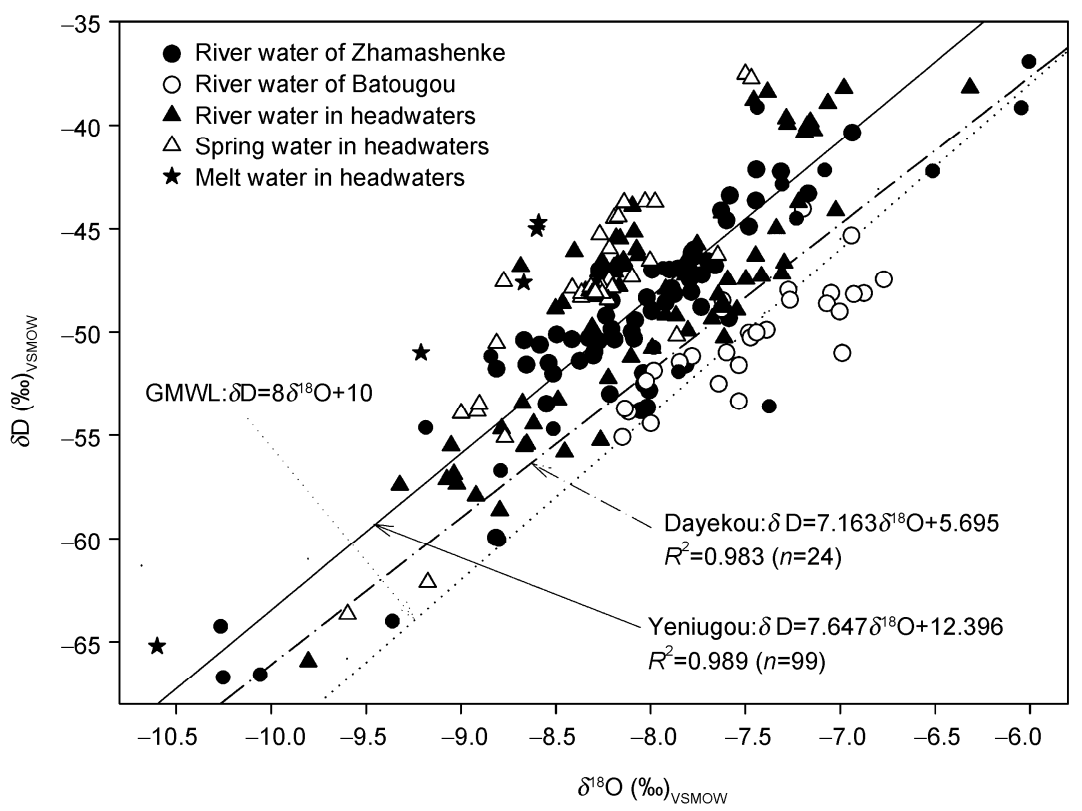

Figure 8 Scatterplots for the relationship between $\delta^{18} \mathrm{O}$ and $\delta \mathrm{D}$ for surface, spring, and melt water, and the relationship between these plots and the local meteoric water lines in the headwaters of the Heihe River basin. 

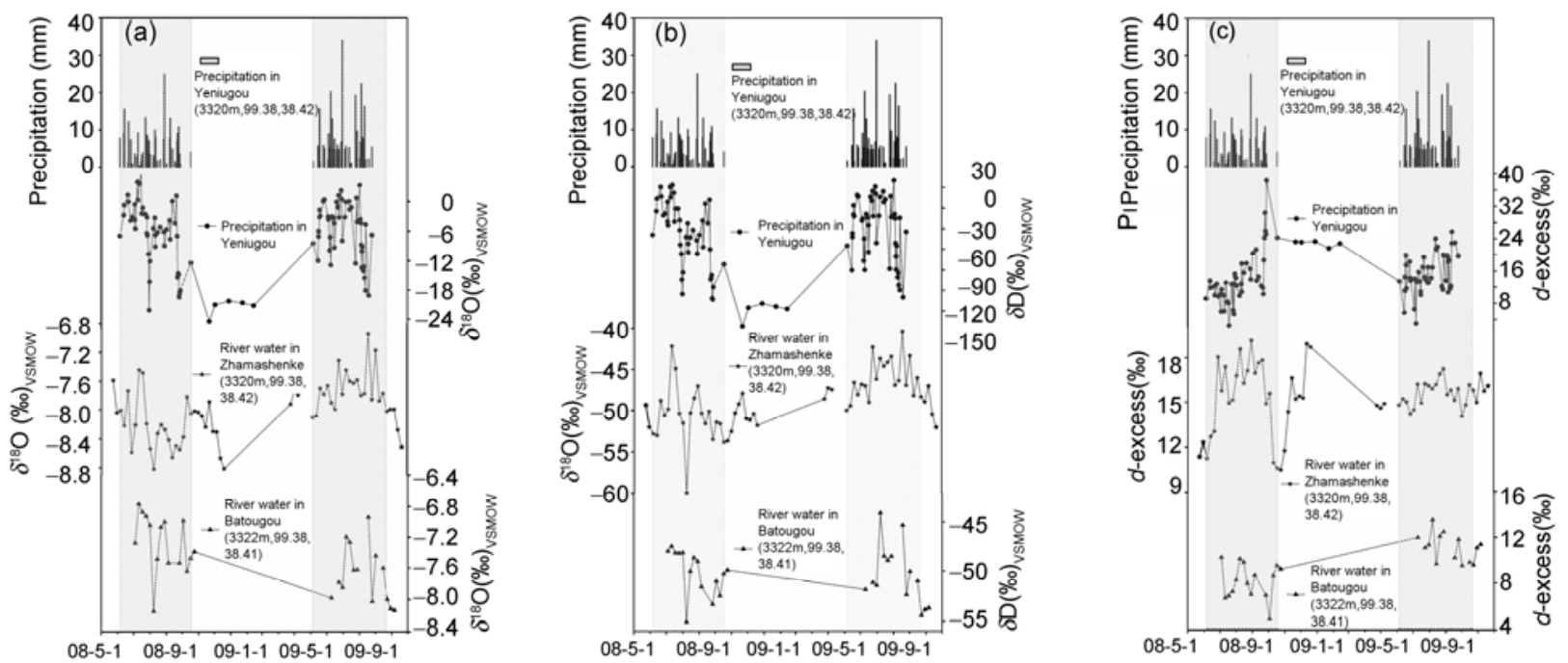

Figure 9 Long-term variations in (a) $\delta^{18} \mathrm{O}$, (b) $\delta \mathrm{D}$, and (c) $d$-excess for precipitation and river water in 2008 and 2009 in the headwaters of the Heihe River basin.

and $d$-excess for river water were significantly lower than those for precipitation is supported by the results of Wang et al.[27]. The variations in $\delta \mathrm{D}, \delta^{18} \mathrm{O}$, and $d$-excess for precipitation at Yeniugou and for water of the Zhamashenke and Batougou Rivers also reveal the supply of precipitation to the rivers in 2008 and 2009 (Figure 9). From June to mid-September, there were similar trends of $\delta \mathrm{D}, \delta^{18} \mathrm{O}$, and $d$-excess for the waters of the Zhamashenke and Batougou Rivers and for the precipitation at Yeniugou, but with the former markedly lagging the latter (by about 8 to $10 \mathrm{~d}$ ). However, after the last 10 days of September, river water $\delta \mathrm{D}$ and $\delta^{18} \mathrm{O}$ remained positive even though precipitation $\delta \mathrm{D}$ and $\delta^{18} \mathrm{O}$ became more negative, and the $d$-excess for the river water did not increase despite a sharp increase in the precipitation $d$-excess. These results indicate that pre- cipitation is a primary recharge source for surface runoff during the rainy season, and that a series of transport flows such as flow through the soil, surface flow, and base flow enter the river after precipitation reaches the ground. Wang et al. [27] also reported that variations in $\delta^{18} \mathrm{O}$ for river water lagged behind those in precipitation $\delta^{18} \mathrm{O}$. To further investigate the contribution of melt water from high-altitude glaciers and spring water to surface runoff, we compared the seasonal variations in $\delta^{18} \mathrm{O}$ for river, melt, and spring water (Figure 10). At altitudes ranging from 3500 to $4159 \mathrm{~m}$ a.s.l., mean $\delta^{18} \mathrm{O}$ values for melt water and river water were $-8.5 \%$ and $-9.1 \%$, respectively, which were significantly more negative than those for spring and river water in the headwaters of the Heihe River basin at the same time. These results indicate that the $\delta^{18} \mathrm{O}$ values for river and melt water

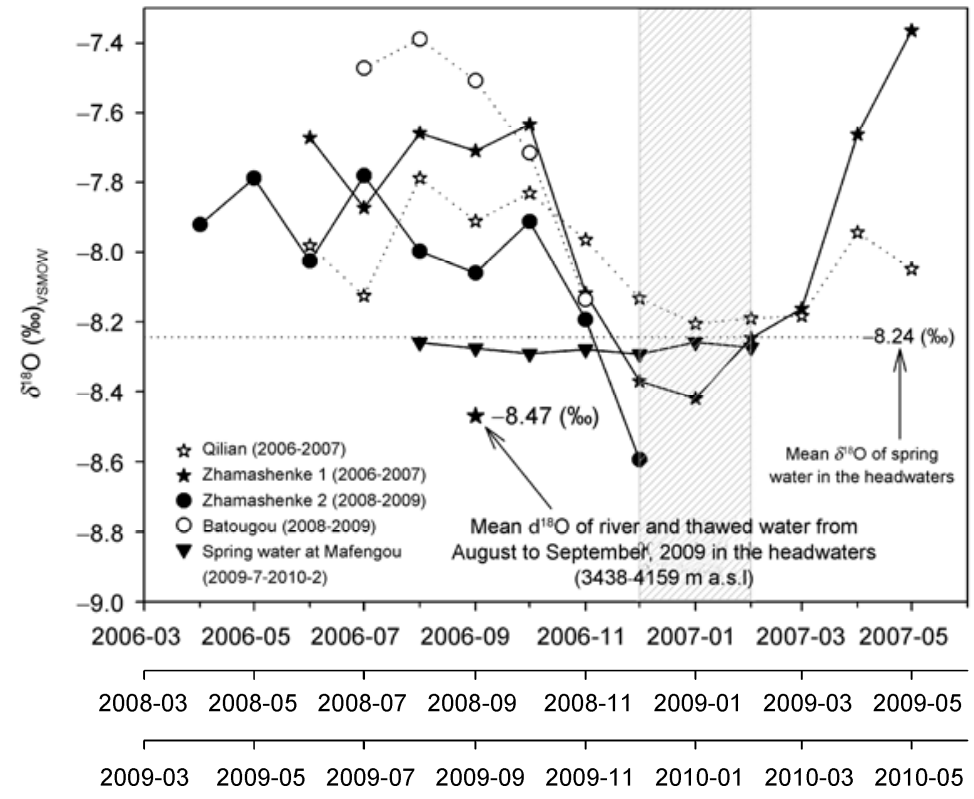

Figure 10 Seasonal variations in $\delta^{18} \mathrm{O}$ of river, melt, and spring water in the headwaters of the Heihe River. $\delta^{18} \mathrm{O}$ data for Qilian and Zhamashenke 1 are from Wang et al. [27]. $\delta^{18} \mathrm{O}$ data for Zhamashenke 2 and Batougou are mean monthly values during 2008 and 2009. The spring water data for Mafengou are the mean monthly $\delta^{18} \mathrm{O}$ values from July 2009 to February 2010. The value of $-8.24 \%$ is the mean $\delta^{18} \mathrm{O}$ value of 51 spring water samples obtained in 2008, 2009, and 2010 in the headwaters of the Heihe River. 
at higher altitudes have a relatively low influence on $\delta^{18} \mathrm{O}$ for surface runoff, and also reveal the minor contributions of melt water and river water at higher altitudes to surface runoff that enters the main stream of the headwaters of the Heihe River basin. This suggestion agrees with previous research results that the contribution of glacier melt water to mountain runoff was less than $10 \%$ [40]. Moreover, the mean $\delta^{18} \mathrm{O}$ value $(-8.2 \%$ ) for spring water in the headwaters from 2008 to 2010 was close to that for spring water from August 2009 to February 2010 at Mafengou (-8.3\%o) and close to the river water $\delta^{18} \mathrm{O}$ value from November to January, suggesting that river water in winter comes mainly from base flow, as spring water.

(ii) Relationship between monthly precipitation and surface runoff. The above results show that mountain runoff entering the headwaters of the Heihe River basin was mainly recharged by precipitation during the rainy season and by spring water during the winter. To further analyze the effects of different water sources on surface runoff, we compared monthly rainfall data from 16 observation stations and monthly runoff data from 12 observation stations, all at altitudes above $2000 \mathrm{~m}$ and with annual precipitation greater than $250 \mathrm{~mm}$ (Figure 11). Our results show that the mountain runoff from May to September accounted for $72.8 \%$ of the annual total and precipitation from May to September accounted for $81.5 \%$ of the annual total, and that the seasonality of the variations in precipitation and runoff agreed well. However, compared with the case for precipitation, the increase in the mountain runoff lagged the peak of precipitation before July, while mountain runoff decreased more slowly than precipitation after July (Figure 11), suggesting that precipitation was the primary source of runoff and that

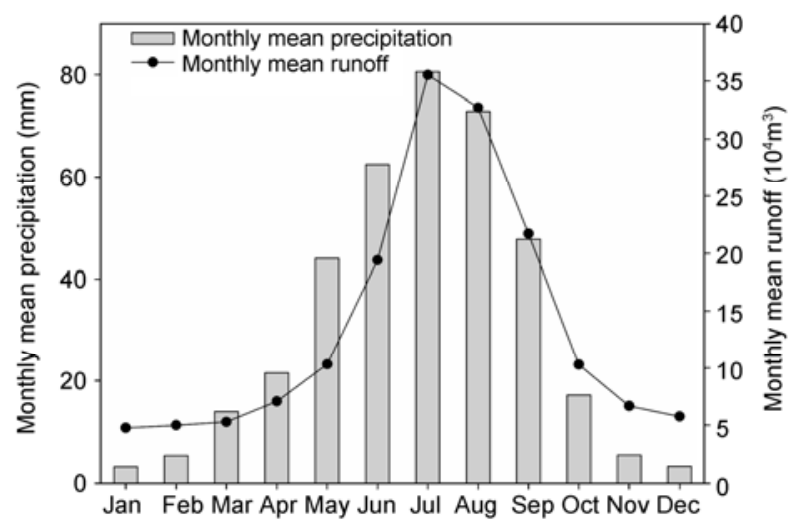

Figure 11 Comparison of monthly mean precipitation and mountain runoff in the headwaters of the Heihe River basin. The data for monthly mean precipitation are taken from 16 observation stations (Xiakouyi, Sunan, Lijiaqiao, Mayinghe, Kangle, Huocheng, Dayekou Xishui, Shuangshusi, Ebo, Qilian, Wudaoban, Binggoutai, Zhamashenke, Wafangcheng, Biandoukou, and Dahuangshan stations); the data for monthly mean runoff are taken from 12 observation stations (Binggou, Fengle, Liyuan, Lijiaqiao, Qilian, Shuangshusi, Sunan, Wafangcheng, Xindi, Yingluoxia, Yingwuzui, and Zhamashenke stations). The altitudes of all stations were higher than $2000 \mathrm{~m}$, and rainfall was greater than $250 \mathrm{~mm}$. runoff responded to changes in precipitation with a time lag. This effect can also be detected in the isotopic behaviors of precipitation and river water (Figure 9). In addition, glaciers and snow in the headwaters of the Heihe River basin melt from mid-May to mid-September [41]. Although the replenishment of rainfall and that of glacial and snow melt water to surface runoff were simultaneous, the similar seasonal variations in the isotopic characteristics of river water and precipitation (Figure 9) and the relationship between the precipitation amount and mountain runoff (Figure 11) confirm that the main supply of mountain runoff was rainfall during the rainy season, with a low contribution from glacial and snow melt water. Our results are supported by previous research on the ratio of precipitation to mountain runoff $[40,42,43]$. However, the mountain runoff was supplied by spring water from November to January, because water froze from December to April and no glacial or snow melt water recharged the mountain runoff. However, further work is needed to investigate the relative contributions of precipitation and melt water to river water at different temporal and spatial scales.

\section{Conclusions}

Precipitation $\delta \mathrm{D}, \delta^{18} \mathrm{O}$, and $d$-excess values indicate that the water entering the headwaters of the Heihe River basin is strongly determined by atmospheric circulation patterns. In the summer, moisture originates from the westerly air masses, and in winter, both westerly and polar air masses contribute to precipitation and snow in the study area. Beyond the northern edge of the summer monsoon and the Pacific monsoon, the seasonality of precipitation $\delta^{18} \mathrm{O}$ for northwestern China, such as in the areas near Lanzhou, Zhangye, Baotou, and Yinchuan, reveals that water was contributed by westerly and polar air masses. Precipitation $\delta^{18} \mathrm{O}$ for Yinchuan is influenced by the summer monsoon during years with strong monsoon intensity. Seasonal variations in precipitation $\delta^{18} \mathrm{O}$ for northeastern China, such as Qiqihar and Changchun closing to the zone affected by the southeastern monsoon in summer, have trends similar to those for Yeniugou in the winter. On this basis, we believe that in northeastern China, regional precipitation is controlled by the southeastern monsoon in summer and by westerly and polar air masses in winter. The surface runoff entering the headwaters of the Heihe River basin comes mainly from precipitation, which mainly occurs from June to September. This period sees the highest mountain runoff, whereas the mountain runoff is mostly supplied by spring water (with a lower flux) in the winter. Therefore, precipitation is an important factor of the water resources of the Heihe River basin. As global climate change continues, variations in precipitation in the headwaters will therefore have a strong influence on the water resources of the Heihe River basin. 
We thank Prof. Wang Ninglian, who shared his data and provided helpful comments and suggestions on how to improve the quality of our paper, and we thank the staff of Nagoya University for confirming the accuracy of our measurements. We especially thank the anonymous reviewers and editor for their helpful advice and suggestions. This work was supported by the National Natural Science Foundation of China (91025016), the West Light Foundation of Western Doctors of the Chinese Academy of Sciences, the West Action Program of the Chinese Academy of Sciences (KZCX2-XB204-03) and the China Postdoctoral Science Foundation (200801244 and 20070420135).

1 Craig H. Isotopic variations in meteoric waters. Science, 1961, 133: 1702-1703

2 Dansgaard W. Stable isotopes in precipitation. Tellus, 1964, 14: 436-468

3 Merlivat L, Jouzel J. Global climate interpretation of the deuterium-oxygen 10 relationship for precipitation. J Geophys Res, 1979, 84: 5029-5033

4 Jouzel J, Merlivat L. Deuterium and oxygen-18 in precipitation: modeling of the isotope effects during snow formation. J Geophys Res, 1984, 89: 11749-11757

5 Siegenthaler $\mathrm{U}$, Oeschger $\mathrm{H}$. Correlation of $\delta^{18} \mathrm{O}$ in precipitation with temperature and altitudes. Nature, 1980, 285: 314-318

6 Merlivat L, Jouzel J. Global climatic interpretation of the deuterium-oxygen 18 relationship for precipitation. J Geophys Res, 1979, 84: 5029-5033

7 Jouzel J, Merlivat L, Lorius C. Deuterium excess in an East Antarctic ice core suggests higher relative humidity at the oceanic surface during the last glacial maximum. Nature, 1982, 299: 688-691

8 Jouzel J, Froehlich K, Schotterer U. Deuterium and oxygen-18 in present-day precipitation: Data and modeling. Hydrol Sci, 1997, 42: 747-763

9 Johnsen S J, Dansgaard W, White J W C. The origin of Arctic precipitation under present and glacial conditions. Tellus B, 1989, 41: $452-468$

10 Feng X H, Faiia A M, Posmentier E S. Seasonality of isotopes in precipitation: A global perspective. J Geophys Res, 2009, 114: D08116, doi:10.1029/2008JD011279

11 Yurtsever Y, Gat J R. Atmospheric waters. Vienna: International Atomic Energy Association, 1981. 103-139

12 Rozanski K, Araguas-Araguas L, Gonfiantini R. Isotopic Pattern in Modern Global Precipitation. Washington: American Geophysical Union, 1993. 1-37

13 Aravena R, Suzuki O, Pena H, et al. Isotopic composition and origin of the precipitation in Northern Chile. Appl Geochem, 1999, 14: $411-422$

14 Tian L D, Yao T D, MacClune K, et al. Stable isotopic variations in west China: A consideration of moisture sources. J Geophys Res, 2007, 112: D10112, doi:10.1029/2006JD007718

15 Lawrence J R, Gedzelman S D, White J W C, et al. Storm trajectories in eastern US: D/H isotopic composition of precipitation. Nature, 1982, 296: 638-640

16 Yamanaka T, Tsujimura M, Oyunbaatar D, et al. Isotopic variation of precipitation over eastern Mongolia and its implication for the atmospheric water cycle. J Hydrol, 2007, 333: 21- 34

17 Hoffman G, Jouzel J, Masson V. Stable water isotopes in atmospheric general circulation models. Hydrol Proc, 2000, 14: 1385-1406

18 Birks S J, Gibson J J, Gourcy L, et al. Maps and animations offer new opportunities for studying the global water cycle. EOS: Trans Am Geophys Union, 2002, 83: 406

19 Tian L D, Yao T D, White J W C, et al. Westerly moisture transport to the middle of Himalayas revealed from the high deuterium excess. Chinese Sci Bull, 2005, 50: 1026-1030

20 Telmer K, Veizer J. Isotopic constraints on the transpiration, evaporation, energy and GPP budgets of a large boreal watershed: Ottawa River basin, Canada. Glob Biogeochem Cycle, 2000, 14: 149-166

21 Gibson J J, Edwards T W D. Regional surfacewater balance and evapotranspiration partitioning from a stable isotope survey of lakes in northern Canada. Glob Biogeochem Cycle, 2002, 16, doi: 10.1029/ 2001GB001839

22 Yonge C J, Goldenberg L, Krouse H R. An isotope study of water bodies along a traverse of southwestern Canada. J Hydrol, 1989, 106: 245-255

23 Longinelli A, Selmo E. Isotopic composition of precipitation in Italy: A first overall map. J Hydrol, 2003, 270: 75-88

24 Chen Z Y, Nie Z L, Zhang G H, et al. Environmental isotopic study on the recharge and residence time of groundwater in the Heihe River Basin, northwestern China. Hydrogeol J, 2006, 14: 1635-1651

25 Chen Z Y, Wan L, Nie Z L, et al. Identification of groundwater recharge in the Heihe Basin using environmental isotopes (in Chinese). Hydrogeol Eng Geol, 2006, 6: 9-14

26 Wang N L, Zhang S B, Pu J C, et al. Seasonal variation of $\delta^{18} \mathrm{O}$ in river water in the upper reaches of Heihe River Basin and its influence factors (in Chinese). J Glaciol Geocryol, 2008, 30: 914-920

27 Wang N L, Zhang S B, He J Q, et al. Tracing the major source area of the mountainous runoff generation of the Heihe River in northwest China using stable isotope technique. Chinese Sci Bull, 2009, 54: 2751-2757

28 Zhang G H, Liu S Y, Xie Y B, et al. Patterns of Water Cycle and Groundwater Evolvement of the Heihe River Basin, Northwestern China. Beijing: Geological Publishing House, 2005. 132, 143,144, 221-223

29 Zhang Y H, Wu Y Q. Characteristics of the $\delta^{18} \mathrm{O}$ in precipitation in the upper and middle reaches of Heihe River (in Chinese). J Glaciol Geocryol, 2007, 29: 440-445

30 Chen G D, Xiao H L, Zhao W Z, et al. Research on Comprehensive Management of the Water-Ecology-Economic System in the Heihe River Basin (in Chinese). Beijing: Science Press, 2009. 8-10

31 Nelson S T. A simple, practical methodology for routine VSMOW/ SLAP normalization of water samples analyzed by continuous flow methods. Rapid Commun. Mass Spectrom, 2000, 14: 1044-1046

32 Clark I D, Fritz P. Environmental Isotopes in Hydrogeology. Canada: CRC Press, 1997. 37

33 Tian L D, Yao T D, Sun W Z, et al. Relationship between $\delta \mathrm{D}$ and $\delta^{18} \mathrm{O}$ in precipitation on north and south of the Tibetan Plateau and moisture recycling. Sci China Ser D-Earth Sci, 2001, 44: 789-796

34 Wang B, LinHo. Rainy season of the Asian-Pacific summer monsoon. J Climatol, 2002, 15: 386-398

35 Tian L D, Yao T D, Numaguti A, et al. Relation between stable isotope in monsoon precipitation in southern Tibetan Plateau and moisture transport history. Sci China Ser D-Earth Sci, 2001, 44(suppl): 267-273

$36 \mathrm{Yu}$ W S, Yao T D, Tian L D, et al. Relationships between $\delta^{18} \mathrm{O}$ in summer precipitation and temperature and moisture trajectories at Muztagata, western China. Sci China Ser D-Earth Sci, 2006, 49: 27-35

37 Yao T D, Zhou X, Yang X X. Indian monsoon influences altitude effect of $\delta^{18} \mathrm{O}$ in precipitation/river water on the Tibetan Plateau. Chinese Sci Bull, 2009, 54: 2724-2731

38 Araguás- Araguás L, Froehlich K, Rozanski K. Stable isotope composition of precipitation over Southeast Asia. J Geophys Res, 1998, 103: 28721-28742

39 Tang X, Sun G W, Qian W H. Study of Northern Edge of the Asian Summer Monsoon (in Chinese). Beijing: China Meteorological Press, 2007. 28-42

40 He J Q, Song G J, Jiang X, et al. Relation between glacial meltwater runoff and mountainous runoff in 2006 in four typical river basins of Heihe River water system (in Chinese). J Desert Res, 2008, 28: 1186-1189

41 Wang J Y, Kang E S, Jin B W. Hydrological function of frozen soil in forest area in the upper reaches of Heihe River (in Chinese). J Northwest Forest Univ, 2001, 16(Suppl): 30-34

42 Li L, Wang Z Y, Wang Q C. Influence of climatic change on flow over the upper reaches of Heihe River (in Chinese). Chin Geogr Sci, 2006, 26: 41-46

43 Yang Y, Chen R S, Ji X B. Variations of glaciers in the Yeniugou Watershed of Heihe River Basin from 1956 to 2003 (in Chinese). J Glaciol Geocryol, 2007, 29: 100-106 